\title{
Evaluasi Efektivitas Manajemen Pembelajaran Guru Produktif Otomotif SMK
}

\author{
Roni Elistanto \\ Universitas Ahmad Dahlan \\ roni_elistanto@yahoo.com
}

Achadi Budi Santosa

Universitas Ahmad Dahlan

budi.santosa@mp.uad.ac.id

Fitri Nur Mahmudah

Universitas Ahmad Dahlan

fitri.mahmudah@mp.uad.ac.id

\begin{abstract}
This study aims to determine (1) the quality of learning materials for automotive productive teacher theory; (2) Preparation and planning of automotive productive teacher learning; (3) Synchronization of theoretical learning with productive teacher practice learning (4) Supervision and follow-up after the evaluation of productive teacher learning. This type of research is an evaluation with a descriptive approach. This research was conducted at SMK Muhammadiyah 1 Moyudan. The respondents were students of automotive engineering expertise programs, all automotive productive teachers, and school principals. The evaluation model used is the Goal Oriented Evaluation Model, which is an evaluation which is oriented towards the objectives of the automotive productive teacher learning management program. Data collection techniques by questionnaire, interview, observation, and documentation. The validity of the instrument through the belp of a competent panel. The results showed: (1) The quality of automotive productive teacher learning materials in SMK Muhammadiyah 1 Moyudan was effective. (2) Preparation and planning of learning of automotive productive teachers in SMK Mubammadiyah 1 Moyudan effectively. (3) Synchronization of theoretical learning with learning practices of automotive productive teachers in SMK Mubammadiyah 1 Moyudan effectively. (4) Supervision and follow-up after the evaluation of the learning of automotive productive teachers of SMK Muhammadiyah 1 Moyudan is effective.
\end{abstract}

Keywords : Evaluation; Effectiveness; Learning Management; Productive Teachers; Vocational School.

Abstrak : Penelitian ini bertujuan untuk mengetahui (1) mutu materi pembelajaran teori guru produktif otomotif; (2) Persiapan dan perencanaan pembelajaran guru produktif otomotif; (3) Sinkronisasi pembelajaran teori dengan pembelajaran praktik guru produktif (4) Pengawasan dan tindak lanjut pasca evaluasi pembelajaran guru produktif. Jenis penelitian ini adalah evaluasi dengan pendekatan deskriptif. Penelitian ini dilakukan di SMK Muhammadiyah 1 Moyudan. Respondennya siswa program keahlian teknik otomotif, semua guru produktif otomotif, dan kepala sekolah. Model evaluasi yang digunakan adalah Goal Oriented Evaluation Model, yaitu evaluasi yang berorientasi pada tujuan program nanajemen pembelajaran guru produktif otomotif. Teknik pengumpulan data dengan angket, wawancara, observasi, dan dokumentasi. Validitas instrumen melalui bantuan panel yang kompeten. Hasil penelitian menunjukkan: (1) Mutu materi pembelajaran guru produktif otomotif SMK Muhammadiyah 1 Moyudan efektif. (2) Persiapan dan perencanaan pembelajaran guru produktif otomotif SMK Muhammadiyah 1 Moyudan efektif. (3) Sinkronisasi pembelajaran teori dengan pembelajaran praktik guru produktif otomotif SMK Muhammadiyah 1 Moyudan efektif. (4) Pengawasan dan tindak lanjut pasca evaluasi pembelajaran guru produktif otomotif SMK Muhammadiyah 1 Moyudan efektif.

Kata Kunci : Evaluasi; Keefektifan; Manajemen Pembelajaran; Guru Produktif; SMK. 


\section{Pendahuluan}

Guru produktif otomotif Sekolah Menengah Kejuruan (SMK) saat ini belum mempunyai waktu yang cukup untuk merencanakan dan mempersiapkan proses pembelajaran yang dituangkan dalam buku administrasi pembelajaran. Guru produktif otomotif SMK Muhammadiyah 1 Moyudan ada sebagian berasal dari generasi tua (generasi X) yang masih cenderung melaksanakan proses pembelajaran secara manual, belum mahir dalam memanfaatkan teknologi dan informasi. Guru produktif otomotif belum maksimal dalam mengajar serta belum konsisten dalam menjaga mutu materi pembelajaran teori dengan pembelajaran praktik (Arends, R.I. 2013; Ali, M. 2009). Sehingga dalam mengajar belum mampu memberikan pembelajaran yang sinkron antara keduanya. Guru belum mampu memberikan bekal pendidikan dan kompetensi yang memadahi bagi siswa sesuai dengan kebutuhan industri untuk menyongsong Revolusi Industri 4.0 di abad 21. Sistem pengawasan dan tindak lanjut pasca evaluasi pembelajaran guru produktif belum sepenuhnya dilakukan dengan melibatkan Guru, Pengawas, Dinas Pendidikan, dan Lembaga Penjaminan Mutu terkait (Arifin, Z. 2009 ; Burhanuddin, A. 2010).

Penelitian yang pernah dilakukan untuk mengevaluasi keefektifan manajemen pembelajaran di suatu sekolah hanya sebatas satu mata pelajaran dengan melibatkan satu orang guru saja. Pendekatan dalam penelitian menggunakan salah satu pendekatan dari pendekatan kuantitatif atau pendekatan kualitatif (Degeng, N.S. 1989).

Pengumpulan data dilakukan dengan menggunakan sebagian dari teknik pengumpulan data. Artikel penelitian ini mengevaluasi tentang keefektifan manajemen pembelajaran guru produktif otomotif di SMK Muhammadiyah 1 Moyudan dengan melibatkan semua guru produktif otomotif, siswa kelas $\mathrm{X}$ jurusan otomotif, dan kepala sekolah. Penelitian ini merupakan penelitian evaluasi dengan pendekatan deskriptif. Model evaluasi yang digunakan adalah Goal Oriented Evaluation Model, yaitu evaluasi yang berorientasi pada tujuan program manajemen pembelajaran guru produktif otomotif SMK Muhammadiyah 1 Moyudan.

Model evaluasi ini cocok diterapkan untuk mengevaluasi program pembelajaran, baik pembelajaran teori maupun pembelajaran praktik, tidak ada keberpihakan, mudah dilaksanakan, waktunya singkat (efektif), dan biayanya murah (efisien). Pendekatan penelitian dilakukan dengan pendekatan deskriptif kuantitatif dan kualitatif. Teknik pengumpulan data menggunakan menggunakan angket (kuesioner), wawancara, observasi, dan dokumentasi agar data yang diungkap lebih akurat dan bisa dipertanggungjawabkan.

Hasibuan \& Mujiono (2006) menjelaskan bahwa guru produktif otomotif diharapkan mampu memastikan agar tujuan pembelajaran tercapai dengan baik, salah satunya dapat melaksanakan proses pembelajaran secara efektif. 
Keefektifan pembelajaran ini dapat tercapai apabila guru produktif otomotif mampu menjaga dengan baik mutu materi pembelajaran teori, menyiapkan dan merencanakan pembelajaran secara benar dan tepat sasaran. Mata pelajaran produktif yang dipelajari/ diajarkan kepada siswa dalam teori harus sesuai dan sinkron dengan pelajaran praktik di laboratorium/ bengkel. Guru produktif otomotif harus mampu melakukan pengawasan serta tindak lanjut pasca evaluasi pembelajaran dengan baik pula. Guru produktif otomotif mampu mengelola proses pembelajaran dengan baik, sehingga manajemen pembelajaran guru produktif otomotif SMK Muhammadiyah 1 Moyudan efektif.

Penelitian ini bertujuan agar mutu materi pembelajaran teori guru produktif otomotif mampu terjaga dengan baik (efektif), persiapan dan perencanaan pembelajaran guru produktif otomotif mampu terlaksana dengan baik, sinkronisasi pembelajaran teori dengan praktik guru produktif otomotif mampu terlaksana dengan baik, dan pengawasan serta tindak lanjut pasca evaluasi pembelajaran guru produktif otomotif mampu terlaksana dengan baik pula. Manfaat penelitian ini diharapkan mampu menambah khasanah ilmu pendidikan, terutama tentang pembelajaran produktif otomotif yang terkait dengan pengelolaan pembelajaran agar tercapai keefektifan manajemen pembelajaran guru produktif otomotif khususnya di SMK Muhammadiyah 1 Moyudan.

Penelitian ini dapat dirumuskan pertanyaan penelitian sebagai berikut:

1) Apakah mutu materi pembelajaran teori guru produktif otomotif SMK Muhammadiyah 1 Moyudan sudah efektif?

2) Apakah persiapan dan perencanaan pembelajaran guru produktif otomotif SMK Muhammadiyah 1 Moyudan sudah efektif?

3) Apakah sinkronisasi pembelajaran teori dengan pembelajaran praktik guru produktif otomotif SMK Muhammadiyah 1 Moyudan sudah efektif?

4) Apakah pengawasan dan tindak lanjut pasca evaluasi pembelajaran guru produktif otomotif SMK Muhammadiyah 1 Moyudan sudah efektif?

\section{Metode Penelitian}

Metode penelitian yang digunakan adalah evaluasi dengan pendekatan deskriptif. Model evaluasi yang digunakan adalah model Goal Oriented Evaluation Model/evaluasi yang berorientasi pada tujuan (Fathurrochman, I., Budiman, D. A., Alamsyahril, \& Kristiawan, M. 2019). Alasan menggunakan evaluasi yang berorientasi pada tujuan pada program manajemen pembelajaran guru produktif otomotif SMK Muhammadiyah 1 Moyudan adalah untuk mengevaluasi ketercapaian keefektifan manajemen pembelajaran guru produktif otomotif SMK dengan program pembelajaran yang telah direncanakan (Fathurrochman, I. 2017; Fathurrochman, I. 2020). 
Data dalam penelitian ini dianalisis secara deskriptif, baik kualitatif maupun kuantitatif dengan bantuan program SPSS versi 24. Teknik analisa data dalam penelitian ini menggunakan statistik deskriptif, statistik yang digunakan untuk menggambarkan data yang telah terkumpul, di mana penulis turut berpartisipasi di lapangan dengan mencatat segala kejadian, melakukan analisis terhadap berbagai dokumen yang ditemukan di lapangan untuk dibuatkan laporan hasil penelitiannya .

Subjek dalam penelitian ini adalah guru produktif otomotif di SMK Muhammadiyah 1 Moyudan, semua akan dijadikan subjek penelitian karena jumlah guru produktif yang ada terbatas. Subjek penelitian ini adalah kepala sekolah, semua guru produktif otomotif, dan siswa program studi Teknik Kendaraan Ringan (TKR) serta Teknik dan Bisnis Sepeda Motor (TBSM) SMK Muhammadiyah 1 Moyudan. Objek penelitian adalah meneliti tentang pengelolaan pembelajaran produktif otomotif dalam kegiatan belajar mengajar di SMK Muhammadiyah 1 Moyudan. Dimaksudkan untuk mengetahui seberapa baik pengelolaan pembelajaran guru produktif otomotif SMK Muhammadiyah 1 Moyudan.

Teknik pengumpulan data pada penelitian ini adalah angket/kuesioner, wawancara, observasi, dan dokumentasi.

1) Metode angket/kuesioner digunakan untuk memperoleh data secara tertulis terhadap mutu pembelajaran teori produktif, persiapan dan perencanaan pembelajaran, sinkronisasi pembelajaran teori dengan praktik, dan pengawasan dan tindak lanjut pasca evaluasi pembelajaran dengan sasaran kepala sekolah, semua guru produktif otomotif, dan semua siswa pada Program Studi: Teknik Otomotif dan Kompetensi Keahlian: Teknik Kendaraan Ringan (TKR) serta Teknik dan Bisnis Sepeda Motor (TBSM) di SMK Muhammadiyah 1 Moyudan. Penelitian ini menggunakan sejumlah kuesioner langsung yang dijawab oleh responden/informan dalam bentuk kuesioner tertutup (memilih alternatif jawaban yang disediakan). Instrumen yang digunakan adalah kuesioner. Alternatif jawaban terdiri dari empat, yaitu: SB (Sangat Baik, skor=4), B (Baik, skor=3), C (Cukup, skor=2), dan TB (Tidak Baik, skor=1).

2) Wawancara ini digunakan untuk metode pengumpulan data yang dilakukan dengan tanya-jawab sepihak yang dilakukan secara sistematik sesuai dengan tujuan penelitian. Wawancara dalam penelitian ini dilakukan kepada guru produktif otomotif SMK Muhammadiyah 1 Moyudan yang paling senior dan dianggap mampu mewakili data yang akan diungkap secara mendalam terkait seberapa baik pengelolaan pembelajaran teori dan praktik. Wawancara dilakukan dengan mengacu pada daftar pertanyaan sesuai instrumen dalam angket. 
3) Observasi digunakan untuk pengamatan langsung terhadap objek dan situasi yang diteliti, yaitu guru produktif otomotif SMK Muhammadiyah 1 Moyudan yang paling senior dalam pengelolaan pembelajaran. Pengamatan langsung dilakukan terhadap berbagai hal kejadian atau situasi nyata pelaksanaan pembelajaran yang dilakukan guru produktif otomotif selama di kelas atau bengkel.

Observasi yang dilakukan dalam hal ini adalah melihat langsung dan mengikuti proses pembelajaran yang dilakukan guru produktif otomotif yang meliputi pembelajaran teori di kelas dan pembelajaran praktik di laboratorium/bengkel. Peneliti melaksanakan pengamatan langsung proses pembelajaran yang dilakukan oleh guru produktif otomotif di dalam kelas/bengkel.

4) Metode Dokumentasi merupakan pedoman yang digunakan untuk menjaring data yang berkaitan dengan pembelajaran yang telah dipersiapkan guru produktif otomotif SMK Muhammadiyah 1 Moyudan. Peneliti melakukan telaah dokumen tentang administrasi pembelajaran terkait keefektifan manajemen pembelajaran guru produktif. Alat yang digunakan untuk pendokumentasian adalah buku atau catatan yang disertai dengan kamera foto.

Objek yang didokumentasi adalah pengelolaan guru produktif otomotif dalam mempersiapkan dan merencanakan pembelajaran, kesesuaian antara pembelajaran teori dengan praktik, serta pelaksanaan pengawasan dan tindak lanjut pasca evaluasi. Dokumentasi meliputi pengumpulan data-data yang terkait dengan perencanaan pembelajaran, antara lain Buku Kerja Guru Produktif yang berisi: SKL, KI/KD, silabus, RPP, KKM, program tahunan, program semester, penilaian, dll. Dokumen dari hasil evaluasi yang berupa nilai ulangan harian dan nilai ujian sekolah. Juga dokumen-dokumen sekolah pendukung yang terkait dengan proses pembelajaran, antara lain: kurikulum sekolah, profil sekolah, dan lain sebagainya yang melibatkan Waka Kurikulum. Berupa foto meliputi kegiatan proses pembelajaran teori pelajaran produktif dan praktik yang sedang berlangsung di dalam kelas/bengkel.

\section{Hasil Penelitian Dan Pembahasan}

\section{1) Mutu Materi Pembelajaran Teori Guru Produktif Otomotif SMK}

Mutu materi pembelajaran merupakan seberapa jauh penyajian informasi guru produktif otomotif atau suatu kemampuan yang mampu membantu siswa mempelajari materi pelajaran teori dengan mudah (Idi, A. 2013; KaufmanThomas. 1980; Pargiyatno. 2017). Mutu materi pembelajaran sebagian besar adalah produk dari mutu kurikulum dan penyajian pelajaran itu sendiri, yaitu yang berkaitan dengan penyajian materi pelajaran, pembahasan materi pelajaran, dan membantu penyelesaian tugas siswa dengan baik. Guru produktif otomotif mampu menyajikan materi pelajaran teori dengan teratur, tertata secara baik, dan 
sistematis sesuai dengan program yang telah direncanakan dalam kurikulum. Guru produktif otomotif memerlukan strategi dalam menghubungkan informasi baru dengan apa yang sudah diketahui siswa. Penyampaian materi pembelajaran teori dapat diperjelas dengan menggunakan media pembelajaran yang berupa peragaan, alat peraga maupun gambar pendukung.

Guru produktif otomotif mampu memantau seberapa baik siswa dalam belajar. Kemampuan guru produktif otomotif dalam menyesuaikan dengan kecepatan pembelajaran. Guru produktif otomotif harus mengetahui kapan memberikan penekanan-penekanan materi ajar atau memberikan materi ajar yang baru, sehingga siswa mampu mengikuti pembelajaran dengan baik dan cukup waktu. Mutu materi pembelajaran yang berkualitas dapat terwujud apabila sekolah beserta semua stakeholder mengikuti peraturan dan standar pendidikan yang diberlakukan pemerintah. Menjaga mutu materi ajar agar tetap baik, proses pembelajaran di SMK diselenggarakan secara menyenangkan, mengacu pada struktur kurikulum, mengikuti perkembangan zaman (mutakhir), menciptakan inovasi, dan dapat memotivasi siswa untuk menemukan sendiri kreativitas masing-masing yang disesuaikan dengan bakat, minat, dan psikologis siswa.

Keefektifan manajemen pembelajaran guru produktif otomotif SMK Muhammadiyah 1 Moyudan dapat dinyatakan dengan Faktor I: "mutu materi pembelajaran teori". Penelitian terkait dengan mutu materi pembelajaran guru produktif otomotif dilakukan terhadap siswa kelas X program studi Teknik Otomotif SMK Muhammadiyah 1 Moyudan yang berjumlah 100 siswa. Hasil dari angket diperoleh data dari Faktor I, analisis item; "mutu materi pembelajaran teori guru produktif otomotif", item soal nomor 1-12 adalah sebagai berikut:

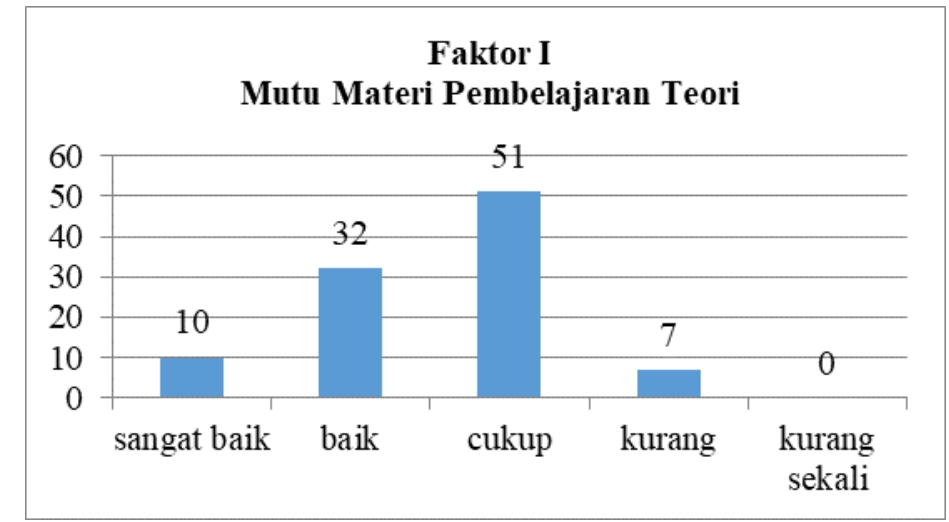

\section{Gambar 1.}

Grafik mutu materi pembelajaran teori

Hasil ini menunjukkan skor dari responden terhadap "mutu materi pembelajaran teori", dari 100 responden ada 51 responden (51\%) yang skornya masuk dalam kategori cukup, 32 responden $(32 \%)$ yang skornya masuk dalam 
kategori baik, 10 responden (10\%) yang skornya masuk dalam kategori sangat baik, 7 responden $(7 \%)$ yang skornya masuk dalam kategori kurang, dan tidak ada responden $(0 \%)$ yang skornya masuk dalam kategori kurang sekali. Rata-rata skor dari 100 responden adalah 33,56 masuk dalam kategori baik. Hasil menunjukkan secara umum "mutu materi pembelajaran teori" masuk dalam kategori efektivitasnya baik. Guru produktif otomotif ditekankan untuk selalu meningkatkan kemampuan akademik sesuai dengan kompetensinya agar mutu materi pembelajaran teori dapat lebih terjaga dengan baik.

\section{2) Persiapan dan Perencanaan Pembelajaran Guru Produktif Otomotif}

Persiapan dan perencanaan pembelajaran wajib dipersiapkan oleh guru produktif otomotif sebelum mengajar di kelas. Perencanaan yang dimaksud di sini lebih menekankan pada persiapan dan perencanaan akademis. Tahapan dalam persiapan dan perencanaan pembelajaran yang harus dilakukan guru produktif otomotif antara lain: merencanakan pembelajaran, melaksanakan proses pembelajaran, dan melaksanakan evaluasi. Setiap guru produktif wajib membuat dan menyusun buku administrasi pembelajaran untuk mata pelajaran produktif. Buku administrasi pembelajaran mencakup kebutuhan keprofesian guru dalam pelaksanaan pembelajaran yang berhubungan langsung antara guru dengan siswa. Silabus dan Rencana Pelaksanaan Pembelajaran wajib dipersiapkan guru produktif pada waktu pembelajaran agar tujuan pembelajaran yang diprogramkan dapat tercapai.

Guru harus mampu mengelola kelas sebaik mungkin, mampu megoptimalkan pembelajaran seefektif mungkin. Guru memiliki tanggung jawab agar proses belajar mengajar berjalan efektif. Materi pelajaran mampu tersalurkan dan mampu dipahami siswa dengan baik. Seorang guru juga harus mampu mengelola waktu agar alokasi waktu dalam proses pembelajaran yang sudah direncanakan dengan materi yang akan diajarkan ke siswa mampu tersampaikan dan terlaksana tepat waktu. Salah satu bagian pendukung keberhasilan dan kelancaran kegiatan belajar mengajar tidak lepas dari persiapan dan perencanaan pembelajaran yang dibuat secara matang. Hal ini tidak lepas dari kelengkapan dokumen administrasi guru sebagai alat penunjang kesuksesan pembelajaran di kelas. Setiap tatap muka di kelas, pembelajaran direncanakan dengan mengacu pada kurikulum yang berlaku. Tahapan dan proses pembelajarannya menyesuaikan dengan kurikulum yang berlaku.

Keefektifan manajemen pembelajaran guru produktif otomotif SMK Muhammadiyah 1 Moyudan dapat dinyatakan dengan Faktor II: "persiapan dan perencanaan pembelajaran". Penelitian terkait dengan persiapan dan perencanaan pembelajaran guru produktif otomotif dilakukan terhadap siswa kelas X program studi Teknik Otomotif SMK Muhammadiyah 1 Moyudan yang berjumlah 100 siswa. Hasil angket diperoleh data dari Faktor II, analisis item; 
"persiapan dan perencanaan pembelajaran guru produktif otomotif", item soal nomor 13-25 adalah sebagai berikut:

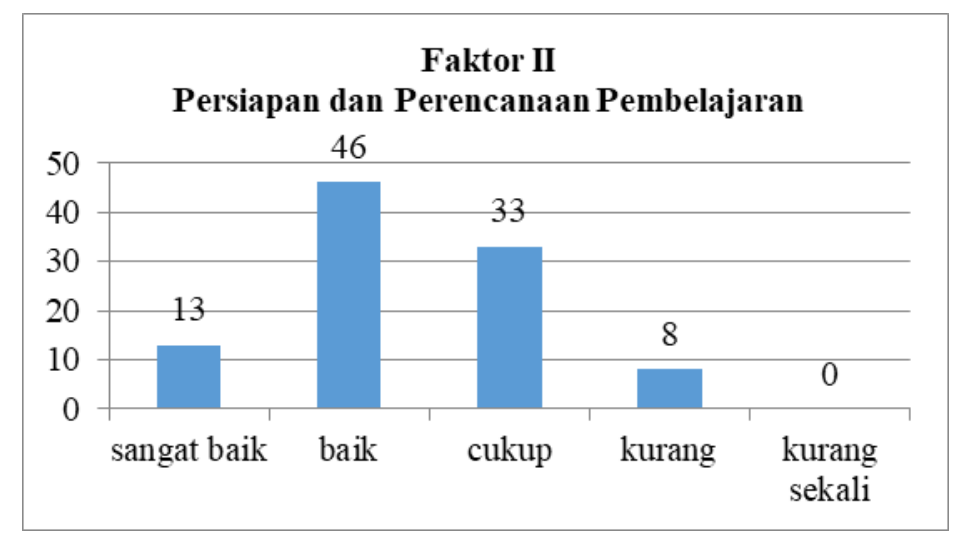

\section{Gambar 2.}

\section{Grafik persiapan dan perencanaan pembelajaran}

Hasil ini menunjukkan skor dari responden terhadap "persiapan dan perencanaan pembelajaran", dari 100 responden ada 46 responden (46\%) yang skornya masuk dalam kategori baik, 33 responden (33\%) yang skornya masuk dalam kategori cukup, 13 responden (13\%) yang skornya masuk dalam kategori sangat baik, 8 responden ( $8 \%$ ) yang skornya masuk dalam kategori kurang, dan tidak ada responden $(0 \%)$ yang skornya masuk dalam kategori kurang sekali. Rata-rata skor dari 100 responden adalah 36,59 masuk dalam kategori baik. Hasil menunjukkan secara umum "persiapan dan perencanaan pembelajaran" masuk dalam kategori efektivitasnya baik.

\section{3) Sinkronisasi Pembelajaran Teori dengan Pembelajaran Praktik}

Pembelajaran teori dalam hai ini merupakan penyampaian materi ajar pelajaran produktif Sekolah Menengah Kejuruan (SMK) dalam bentuk teori pada kegiatan belajar mengajar yang dilakukan oleh guru produktif dengan siswa untuk mencapai kompetensi yang diharapkan bersama. Materi ajar pelajaran produktif yang dimaksud adalah semua mata pelajaran produktif yang diampu oleh guru produktif pada Program Keahlian Teknik Otomotif, Kompetensi Keahlian Teknik Kendaraan Ringan yang terbagi menjadi dua bagian, yaitu Dasar Program Keahlian dan Kompetensi Keahlian. Dasar Program Keahlian meliputi mata pelajaran antara lain: Gambar Teknik Otomotif, Teknologi Dasar Otomotif, dan Pekerjaan Dasar Teknik Otomotif. Kompetensi Kealian meliputi mata pelajaran antara lain: Pemeliharaan Mesin Kendaraan Ringan, Pemeliharaan Sasis dan Pemindah Tenaga Ringan, Pemeliharaan Kelistrikan Kendaraan Ringan (Suharsimi, A. 1992; Suharsimi, A. 2012).

Pembelajaran praktik merupakan suatu cara mengajar dengan memberi kesempatan kepada siswa untuk menemukan suatu fakta yang diperlukan atau 
ingin diketahuinya (Soekartawi. 1995; Soetopo, H. 2005). Pembelajaran praktik adalah proses pembelajaran di mana siswa sebagai pelaku mengalami sendiri, mengikuti proses, mengamati objek, menganalisis, membuktikan dan menarik kesimpulan dari suatu objek. Materi yang dipelajari dapat dipecahkan permasalahannya dengan melakukan pengamatan induktif (Suharsimi, A., Jabar, C.S.A. 2014; Surachmi, S. 2011).

Pembelajaran praktik dilakukan agar siswa mampu mengasah kemampuan berpikir seiring dengan melatih keterampilan (Santrock, J.W. 2014; Sedarmayanti. 2001). Salah satu metode yag dapat digunakan untuk mengintegrasikan kemampuan berpikir dan keterampilan tersebut adalah metode praktikum, yaitu cara melaksanakan secara nyata apa yang tersebut dalam teori. Merupakan bagian dari pembelajaran yang bertujuan agar siswa mendapat kesempatan untuk menguji dan melaksanakan dari keadaan nyata apa yang diperoleh dari pembelajaran teori. Pembelajaran praktik otomotif merupakan kegiatan belajar mengajar yang dilakukan oleh siswa dalam rangka merealisasikan dan pembuktian pembelajaran teori khususnya pelajaran produktif otomotif yang telah didapatkan sebelumnya guna membentuk siswa menjadi manusia yang mempunyai keterampilan (skill) dan prakarya. Diharapkan siswa mempunyai pendidikan kecakapan vokasional untuk siap kerja dan mampu menjadi wirausaha (Slavin, R.E. 2011; Slavin, R.E. 2011).

Sinkronisasi antara pembelajaran teori dengan pembelajaran praktik khusunya mata pelajaran produktif otomotif sangat dibutuhkan (Pidarta, M. 1988; Samana, A. 1994). Guru produktif otomotif SMK harus mampu mengajar mata pelajaran produktif/ kejuruan secara kompeten sesuai dengan kompetensinya masing-masing, baik dalam hal pembelajaran teori maupun pembelajaran praktik otomotif. Pembelajaran teori dengan pembelajaran praktik harus sesuai dan cocok, jangan sampai pembelajaran teori yang disampaikan guru produktif otomotif berbeda dengan pembelajaran praktik yang berlangsung. Terciptanya kesesuaian antara pembelajaran teori dengan pembelajaran praktik agar tercapai tujuan pembelajaran yang telah diprogramkan sesuai dengan kurikulum yang berlaku. Dengan demikian keefektifan pembelajaran juga akan tercapai sesuai dengan program yang telah direncanakan sebelumnya.

Keefektifan manajemen pembelajaran guru produktif otomotif SMK Muhammadiyah 1 Moyudan dapat dinyatakan dengan Faktor III: "sinkronisasi pembelajaran teori dengan praktik". Penelitian terkait dengan sinkronisasi pembelajaran teori dengan praktik guru produktif otomotif dilakukan terhadap siswa kelas X program studi Teknik Otomotif SMK Muhammadiyah 1 Moyudan yang berjumlah 100 siswa. Hasil angket diperoleh data dari Faktor III, analisis item; "sinkronisasi pembelajaran teori dengan praktik guru produktif otomotif", item soal nomor 26-30 adalah sebagai berikut: 


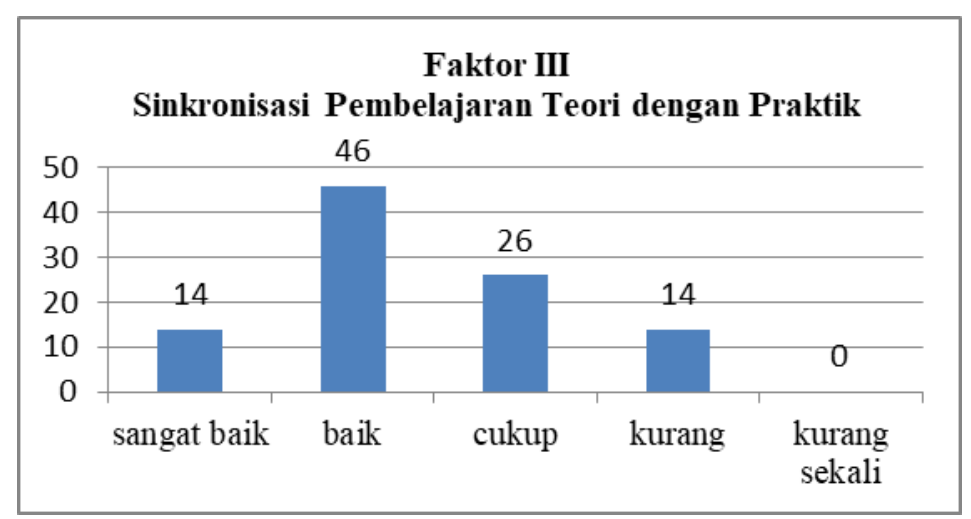

Gambar 3.

Grafik sinkronisasi pembelajaran teori dengan praktik

Hasil ini menunjukkan skor dari responden terhadap "sinkronisasi pembelajaran teori dengan praktik", dari 100 responden ada 46 responden $(46 \%)$ yang skornya masuk dalam kategori baik, 26 responden $(26 \%)$ yang skornya masuk dalam kategori cukup, 14 responden (14\%) yang skornya masuk dalam kategori sangat baik, 14 responden (14\%) yang skornya masuk dalam kategori kurang, dan tidak ada responden $(0 \%)$ yang skornya masuk dalam kategori kurang sekali. Rata-rata skor dari 100 responden adalah 14,04 masuk dalam kategori baik. Hasil menunjukkan secara umum "sinkronisasi pembelajaran teori dengan praktik" masuk dalam kategori efektivitasnya baik.

\section{4) Pengawasan dan Tindak Lanjut Pasca Evaluasi Pembelajaran Guru Produktif}

Pelaksanaan pengawasan bertujuan untuk meningkatkan mutu pembelajaran secara berkelanjutan (Syah, M. 1999; Wirawan. 2012). Sistem pengawasan dapat dilaksanakan secara internal dan eksternal. Secara internal dilaksanakan oleh Kepala Sekolah, sedangkan pengawasan eksternal dilakukan oleh Pengawas Sekolah dan Dinas Pendidikan serta Lembaga Penjaminan Mutu Pendidikan terkait. Kepala Sekolah dapat melakukan pengawasan dalam bentuk Supervisi Akademik dan Supervisi Klinis kepada para guru produktif sehingga mutu pembelajarannya dapat terjaga secara berkesinambungan.

Pengawasan dilakukan mulai dari pemantauan, supervisi, dan pelaporan. Sistem pengawasan ini tidak sebatas pada proses pembelajarannya, tetapi juga dilakukan pasca evaluasi pembelajaran. Supervisi akademik merupakan suatu rangkaian kegiatan dalam rangka membantu guru produktif otomotif untuk mengembangkan kemampuan akademiknya dalam mengelola proses pembelajaran produktif otomotif untuk mencapai tujuan pembelajaran. Sedangkan supervisi klinis adalah suatu kegiatan dalam rangka pembinaan untuk meningkatkan kinerja guru produktif otomotif (performance) dalam mengelola 
proses pembelajaran dengan tujuan untuk mencapai pengembangan profesional dan motivasi kinerja guru produktif otomotif.

Pengawasan perlu dilakukan untuk mengontrol mutu pembelajaran yang sudah berlangsung secara objektif dan transparan. Pengawasan ini dilakukan oleh Kepala Sekolah, Pengawas, dan Dinas Pendidikan dan Lembaga Penjaminan Mutu yang terkait. Apabila diketemukan hal-hal yang tidak sesuai atau penurunan mutu pembelajaran, maka perlu dilakukan tindak lanjut secara bersama-sama untuk menangani kekurangan-kekurangan tersebut. Sistem pengawasan pasca evaluasi yang baik tanpa didukung oleh tindak lanjut yang baik pula, maka sulit untuk meningkatkan kualitas dan mutu pendidikan yang mutakhir. Pemberian hadiah (reward) wajib diberikan kepada guru produktif otomotif yang berprestasi dan mempunyai kenerja tinggi. Sebagai program tindak lanjut yang lain adalah meningkatkan dan mengembangkan keprofesionalan guru produktif otomotif, baik melalui pelatihan-pelatihan maupun peningkatkatan kualifikasi akademik dan studi lanjut.

Keefektifan manajemen pembelajaran guru produktif otomotif SMK Muhammadiyah 1 Moyudan dapat dinyatakan dengan Faktor IV: "pengawasan dan tindak lanjut pasca evaluasi pembelajaran". Penelitian terkait dengan pengawasan dan tindak lanjut pasca evaluasi pembelajaran guru produktif otomotif dilakukan terhadap siswa kelas X program studi Teknik Otomotif SMK Muhammadiyah 1 Moyudan yang berjumlah 100 siswa. Hasil angket diperoleh data dari Faktor IV, analisis item; "pengawasan dan tindak lanjut pasca evaluasi pembelajaran guru produktif otomotif", item soal nomor 31-40 adalah sebagai berikut:

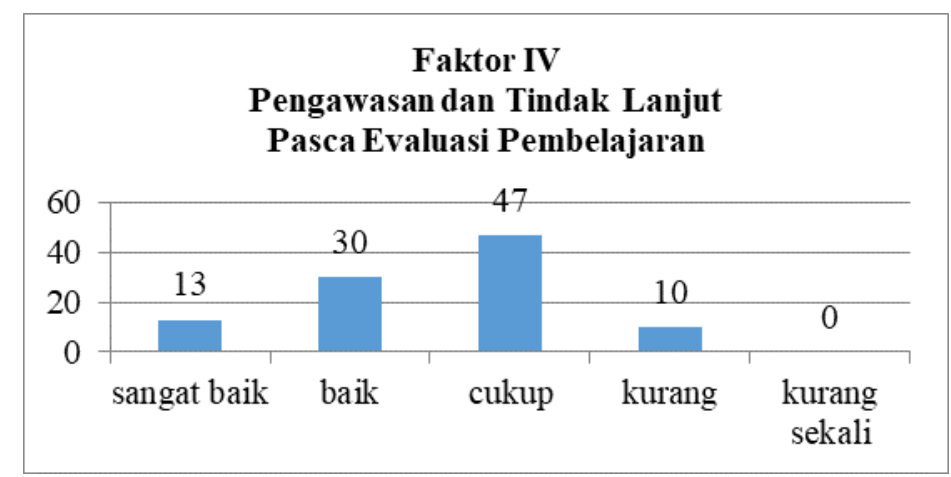

\section{Gambar 4.}

Grafik pengawasan dan tindak lanjut pasca evaluasi pembelajaran

Hasil ini menunjukkan skor dari responden terhadap "pengawasan dan tindak lanjut pasca evaluasi pembelajaran", dari 100 responden ada 47 responden $(47 \%)$ yang skornya masuk dalam kategori cukup, 30 responden 
(30\%) yang skornya masuk dalam kategori baik, 13 responden (13\%) yang skornya masuk dalam kategori sangat baik, 10 responden $(10 \%)$ yang skornya masuk dalam kategori kurang, dan tidak ada responden $(0 \%)$ yang skornya masuk dalam kategori kurang sekali. Rata-rata skor dari 100 responden adalah 27,50 masuk dalam kategori cukup. Hasil menunjukkan secara umum "pengawasan dan tindak lanjut pasca evaluasi pembelajaran" masuk dalam kategori efektivitasnya cukup. Guru poduktif otomotif lebih meningkatkan pengawasan dan tindak lanjut pasca evaluasi pembelajaran dengan bekerjasama dengan pengawas pendidikan dan instansi terkait agar pembelajaran lebih efektif dan tercapai tujuan pembelajaran yang diharapkan.

\section{Kesimpulan}

Hasil penelitian adalah: (1) Mutu materi pembelajaran teori guru produktif otomotif SMK Muhammadiyah 1 Moyudan efektif. Hasil menunjukkan; 51\% skor responden kategori cukup, 32\% kategori baik, 10\% kategori sangat baik, 7\% kategori kurang, dan 0\% kategori kurang sekali. (2) Persiapan dan perencanaan pembelajaran guru produktif otomotif SMK Muhammadiyah 1 Moyudan efektif. Hasil menunjukkan; 46\% skor responden kategori baik, 33\% kategori cukup, 13\% kategori sangat baik, 8\% kategori kurang, dan 0\% kategori kurang sekali. (3) Sinkronisasi pembelajaran teori dengan pembelajaran praktik guru produktif otomotif SMK Muhammadiyah 1 Moyudan efektif: hasil menunjukkan; 46\% skor responden kategori baik, 26\% kategori cukup, 14\% kategori sangat baik, 14\% kategori kurang, dan 0\% kategori kurang sekali. (4) Pengawasan dan tindak lanjut pasca evaluasi pembelajaran guru produktif otomotif SMK Muhammadiyah 1 Moyudan efektif. Hasil menunjukkan; 47\% skor responden kategori cukup, 30\% kategori baik, 13\% kategori sangat baik, 10\% kategori kurang, dan 0\% kategori kurang sekali.

Hasil penelitian yang telah dilakukan, memiliki beberapa saran yaitu: (1) Hasil penelitian menyatakan bahwa manajemen pembelajaran guru produktif otomotif efektif. Diharapkan kepada guru produktif otomotif untuk selalu meningkatkan kemampuan akademik sesuai kompetensinya mengikuti perkembangan dan kemajuan teknologi di bidang otomotif. (2) Guru produktif otomotif diharapkan lebih meningkatkan pengawasan dan tindak lanjut pasca evaluasi pembelajaran bekerjasama dengan pengawas pendidikan dan instansi terkait agar tujuan pembelajaran yang diharapkan mampu tercapai dengan baik. (3) Dalam rangka mengimbangi perkembangan dan kemajuan teknologi yang semakin pesat, maka pengadaan sarana dan prasarana sekolah khususnya peralatan praktik, media pembelajaran, dan laboratorium/ bengkel otomotif perlu ditingkatkan. (4) Adanya kurikulum berbasis industri atau pembelajaran berbasis industri (teaching factory) sangat membantu dalam mencapai keberhasilan dan menjaga mutu pembelajaran di sekolah. Perlu ditingkatkan adanya kerja sama (Memorandum of Understanding/ MoU) sebanyak- 
banyaknya dengan DU/ DI. Materi pembelajaran pada kurikulum sekolah dapat disesuaikan dengan kebutuhan industri (DU/ DI). Dengan demikian lulusan (output) dapat terserap secara mudah pada DU/ DI. (5) Guru produktif otomotif diharapkan mampu mengenal masing-masing pribadi siswa lebih baik lagi dengan berbagai macam latar belakangnya. Dengan mengenal tipe dan karakter siswa, diharapkan dalam kegiatan pembelajaran produktif otomotif mampu berjalan dengan baik/ efektif. Sehingga siswa akan mampu berpikir kritis, kreatif, komunikatif, dan kolaboratif dengan karakter yang baik. Siswa diharapkan nantinya siap kerja dan siswa mampu berwirausaha.

\section{Daftar Pustaka}

Ali, M. (2009). Guru dalam Proses Belajar Mengajar. Bandung: Sinar Baru Algesindo.

Anggraeni, D.A.N. (2010). "Keefektifan Manajemen Pembelajaran IPA di SMP Negeri Kabupaten Temanggung”. UNY: S2 Tesis.

Arends, R.I. (2013). Belajar untuk Mengajar. Jakarta: Salemba Humanika.

Arifin, Z. (2009). Evaluasi Pembelajaran. Bandung: PT. Remaja Rosdakarya.

Burhanuddin, A. (2010). "Keefektifan Manajemen Sekolah Bertaraf Internasional di SMA Negeri Kota Yogyakarta". Jurnal Penelitian Pendidikan.

Degeng, N.S. (1989). Ilmu Pengajaran Taksonomi Variabel. Jakarta: Dit Jen Dikti P2LPTK Jakarta.

Depdikbud. (2003). Undang-Undang RI Nomor 20 Tahun 2003 tentang Sistem Pendidikan Nasional. Jakarta.

Depdikbud. (2004). Kurukulum SMK edisi 2004. Jakarta: Direktorat Jenderal Pendidikan Menengah dan Kejuruan.

Depdikbud. (2005). Peraturan Pemerintah Nomor 19 Tahun 2005 tentang Sistem Pendidikan Nasional. Jakarta.

Direktorat PSMK. (2016). Pola Kebijakan Pengembangan Guru Produktif Berdarkan Inpres Nomor 9 Tahun 2016. Jakarta.

Direktorat PSMK. (2018). Strategi Membentuk Kecakapan Abad 21 dalam Implementasi Kurikulum SMK. Jakarta.

Dirjen Dikdasmen. (2018). Peraturan Dirjen Dikdasmen tentang Struktur Kurikulum SMK/MAK Nomor: 07/D.D5/KK/2018. Jakarta.

Djamarah, S.B. \& Zain, A. (2002). Strategi Belajar Mengajar. Jakarta: Rineka Cipta. 
114 | TADBIR : Jurnal Studi Manajemen Pendidikan, Vol. 4, No. 1, Mei 2020

Fathurrochman, I. (2017). Pengembangan Kompetensi Pegawai Aparatur Sipil Negara (ASN) Sekolah Tinggi Agama Islam Negeri (STAIN) Curup Melalui Metode Pendidikan Dan Pelatihan. Manajer Pendidikan, 11(2).

Fathurrochman, I. (2020). Pendidikan Sebagai Media Integrasi Agama Dan Sains Dalam Era Revolusi Industri 4.0. Jurnal Literasiologi, 3(1).

Fathurrochman, I., Budiman, D. A., Alamsyahril, \& Kristiawan, M. (2019). Revitalization Management Of Islamic Boarding School Preventing The Radicalism. Restaurant Business, (10), 495-505. Retrieved from https://journals.eduindex.org/index.php/rb/article/view/9462.

Hasibuan \& Mujiono. (2006). Proses Belajar Mengajar. Bandung: PT. Remaja Rosdakarya.

Idi, A. (2013). Pengembangan Kurikulum: Teori dan Praktik. Jogjakarta: ArRuzz.

Kaufman-Thomas. (1980). Evaluation Without Fear. New Vewpoints. A Division Franklin Watts. 730 Fifth Avenue. New York 10019.

Kemdikbud. (2013). Peraturan Menteri Pendidikan dan Kebudayaan RI Nomor 32 Tahun 2013 tentang Perubahan atas Peraturan Pemerintah Nomor 19 Tahun 2005 tentang Standar Nasional Pendidikan. Jakarta.

Kemdikbud. (2016). Peraturan Menteri Pendidikan dan Kebudayaan RI Nomor 22 Tahun 2016 tentang Standar Proses Pendidikan Dasar dan Menengah. Jakarta.

Kemdikbud. (2017). Peraturan Pemerintah Nomor 19 Tahun 2017 tentang Guru. Jakarta.

Kreitner, R. (1983). "Management". Houghton Mifflin Company Boston. Dallas. Genewa, Illionis. Hopewell, New Jersey. Palo Alto. London.

Medley, D.M. (1977). Teacher Competence and Teacher Effectiveness. American Association for Teacher Education. One Duporit Circle, Suite 610. Washington D.C. 20036. Jurnal Internasional.

Muhyadi. (1989). Organisasi: Teori, Struktur dan Proses. Jakarta: P2LPTK DIKTI Departemen Pendidikan dan Kebudayaan.

Pargiyatno. (2017). "Keefektifan Manajemen Sekolah Jurusan Kelautan di SMK Negeri 1 Sanden Kabupaten Bantul”. UAD: S2 Thesis.

Pidarta, M. (1988). Manajemen Pendidikan Indonesia. Jakarta: PT Rineka Cipta. Samana, A. (1994). Profesionalisme Keguruan. Yogyakarta: Kanisius. 
Santrock, J.W. (2014). Psikologi Pendidikan. Jakarta: Salemba Humanika.

Sedarmayanti. (2001). Sumber Daya Manusia dan Produktivitas Kerja. Bandung: Mandar Maju.

Slavin, R.E. (2011). Psikologi Pendidikan: Teori dan Praktik. Edisi Kesembilan Jilid 1. Jakarta: PT. Indeks.

Slavin, R.E. (2011). Psikologi Pendidikan: Teori dan Praktik. Edisi Kesembilan Jilid 2. Jakarta: PT. Indeks.

Soekartawi. (1995). Meningkatkan Efektivitas Mengajar. Jakarta: PT. Dunia Pustaka Jaya.

Soetopo, H. (2005). "Keefektifan Organisasi Perguruan Tinggi dalam Penjaminan Mutu Pendidikan". Uiversitas Negeri Malang: Pidato Pengukuhan Guru Besar dalam Bidang Manajemen Pendidikan pada Fakultas Ilmu Pendidikan.

Suharsimi, A. (1992). Dasar-Dasar Evaluasi Pendidikan. Jakarta: Bumi Aksara.

Suharsimi, A. (2012). Dasar-Dasar Evaluasi Pendidikan. Jakarta: Bumi Aksara.

Suharsimi, A., Jabar, C.S.A. (2014). Evaluasi Program Pendidikan. Jakarta: Bumi Aksara.

Surachmi, S. (2011). "Efektivitas Dimensi Internal Kepala Sekolah dalam Kepemimpinan Pembelajaran". Cakrawala Pendidikan. Jurnal Penelitian Internasional.

Syah, M. (1999). Psikologi Pendidikan dengan Pendekatan Baru. Jakarta: Remaja Rosda Karya.

Wirawan. (2012). Evaluasi: Teori, Model, Standar, Aplikasi, dan Profesi. Jakarta: Rajawali Pers. 
116 | TADBIR : Jurnal Studi Manajemen Pendidikan, Vol. 4, No. 1, Mei 2020

This page belongs to the TADBIR : Jurnal Studi Manajemen Pendidikan

TADBIR : Jurnal Studi Manajemen Pendidikan vol. 4 , no. 1, Mei 2020

IAIN Curup - Bengkulu | p-ISSN 2580-3581; e-ISSN 2580-5037 